\title{
Decomposition of the single-phase high-entropy alloy CrMnFeCoNi after prolonged anneals at intermediate temperatures
}

\author{
F. Otto ${ }^{1}$, A. Dlouhý ${ }^{2}$, K.G. Pradeep ${ }^{3}$, M. Kuběnová ${ }^{2}$, D. Raabe ${ }^{3}$, G. Eggeler ${ }^{1}$, E.P. George ${ }^{1 *}$ \\ ${ }^{1}$ Institute for Materials, Ruhr University Bochum, 44801 Bochum, Germany \\ ${ }^{2}$ Institute of Physics of Materials, Academy of Sciences of the Czech Republic, 61662 Brno, \\ Czech Republic
}

${ }^{3}$ Max-Planck-Institut für Eisenforschung, Max-Planck-Straße 1, 40237 Düsseldorf, Germany

*Corresponding author: email: easo.george@,rub.de; tel: +49 (0) 2343225902

\begin{abstract}
Among the vast number of multi-principal-element alloys that are referred to as highentropy alloys (HEAs) in the literature, only a limited number solidify as single-phase solid solutions. The equiatomic $\mathrm{HEA}, \mathrm{CrMnFeCoNi}$, is a face-centered cubic (FCC) prototype of this class and has attracted much attention recently because of its interesting mechanical properties. Here we evaluate its phase stability after very long anneals of 500 days at 500$900{ }^{\circ} \mathrm{C}$ during which it is reasonable to expect thermodynamic equilibrium to have been established. Microstructural analyses were performed using complementary analysis techniques including scanning and transmission electron microscopy (SEM/TEM/STEM), energy dispersive X-ray (EDX) spectroscopy, selected area electron diffraction (SAD), and atom probe tomography (APT). We show that the alloy is a single-phase solid solution after homogenization for 2 days at $1200{ }^{\circ} \mathrm{C}$ and remains in this state after a subsequent anneal at $900{ }^{\circ} \mathrm{C}$ for 500 days. However, it is unstable and forms second-phase precipitates at 700 and $500{ }^{\circ} \mathrm{C}$. A Cr-rich $\sigma$ phase forms at $700{ }^{\circ} \mathrm{C}$, whereas three different phases $\left(\mathrm{L} 10_{0}-\mathrm{NiMn}, \mathrm{B} 2-\right.$
\end{abstract}


$\mathrm{FeCo}$ and a $\mathrm{Cr}$-rich body-centered cubic, $\mathrm{BCC}$, phase) precipitate at $500{ }^{\circ} \mathrm{C}$. These precipitates are located mostly at grain boundaries, but also form at intragranular inclusions/pores, indicative of heterogeneous nucleation. Since there is limited entropic stabilization of the solid solution state even in the extensively investigated $\mathrm{CrMnFeCoNi}$ alloy, the stability of other HEAs currently thought to be solid solutions should be carefully evaluated - especially if they are being considered for applications in vulnerable temperature ranges.

Keywords: High-entropy alloy; phase stability; solid solution; aging; phase transformations

\section{Introduction}

Multi-principal-element alloys (or high-entropy alloys as they are often referred to in the literature) have attracted worldwide attention because they open up a vast compositional space in which new materials may be discovered [1]. An intriguing aspect of multi-principalelement alloys containing five or more elements in nearly equiatomic concentrations is that their high configurational entropies (assuming that they are ideal random mixtures) might favor the formation of solid solutions over the precipitation of brittle intermetallic compounds [2]. And, indeed, there are several reports in the literature of solid solution HEAs that appear to lend credence to the notion of entropic stabilization [e.g. 1,3-22].

One of the extensively investigated HEAs is the equiatomic CrMnFeCoNi alloy that solidifies as a single-phase solid solution with the FCC structure [8]. It has been produced by arc [7,9,10,23,24] or induction [25] melting, and deformation processed by hot rolling [9], room temperature rolling [7,10,23], cryogenic rolling [26], or room temperature swaging [25]. It has also been severely deformed (shear strains of $5000 \%$ or more) by high-pressure torsion (HPT) at room temperature [27]. Recrystallization during hot rolling [9] and after cold rolling or swaging $[7,10,25]$ produces single-phase equiaxed microstructures with grain sizes 
ranging from a few to hundreds of $\mu \mathrm{m}$, whereas HPT produces a much smaller grain size of $\sim 50 \mathrm{~nm}[27]$.

At least part of the interest in the CrMnFeCoNi HEA stems from its fascinating mechanical behavior, including increasing strength and ductility with decreasing temperature $[9,10]$ combined with relatively weak strain rate dependence [9]. It has excellent fracture toughness at room temperature, which remains high down to cryogenic temperatures [28]. The material also shows a grain size dependence of strength [10,27] and hardness [7]. Based on the limited grain size range $(\sim 4-26 \mu \mathrm{m})$ investigated in [7], hardness appears to follow classical Hall-Petch behavior but with a higher slope than for many FCC metals.

Structural analyses at multiple length scales using a variety of techniques including optical microscopy (OM) [7,29], X-ray diffraction (XRD) [8,9,11,30,31], SEM/TEM [10,23] and APT [32] have shown that CrMnFeCoNi is a single-phase FCC solid solution after homogenization at temperatures of $1000{ }^{\circ} \mathrm{C}$ or higher for times up to two days, as well as after recrystallization at temperatures $\geq 800{ }^{\circ} \mathrm{C}$ for 1 hour. However, two recent studies have shown that the alloy decomposes into multiple phases at lower temperatures as summarized below.

In the first study, Schuh et al. [27] produced material with a grain size of $\sim 50 \mathrm{~nm}$ by HPT and showed using APT and TEM that it was single-phase down to the atomic scale in the severely deformed state. However, precipitates were observed in the alloy after annealing at $450{ }^{\circ} \mathrm{C}$, starting with two phases (a Cr-rich phase and a phase rich in $\mathrm{Ni}+\mathrm{Mn}$ ) at times as short as 5 minutes, followed by a third phase rich in $\mathrm{Fe}+\mathrm{Co}$ at longer times of around 15 hours. However, the crystal structures of these phases were not identified and the study left open the question whether the nanoscale (and possibly non-equilibrium) microstructure after HPT could have influenced subsequent phase evolution. 
Recently, Pickering et al. [24] annealed an arc-melted and homogenized button of the CrMnFeCoNi alloy for times ranging from 125 to 1000 hours at $700{ }^{\circ} \mathrm{C}$ and showed definitively, using EDX mapping in the SEM and SAD in the TEM, that a Cr-rich $\sigma$ phase formed after 500 hours and that its volume fraction increased after longer anneals of 1000 hours. They also found $\mathrm{M}_{23} \mathrm{C}_{6}$ type carbides after a shorter anneal of 125 hours, which they attributed to carbon contamination from either the melting furnace or the raw materials. Their study thus showed that even coarse-grained $\mathrm{CrMnFeCoNi}$ is unstable and decomposes into a Cr-rich $\sigma$ phase at $700{ }^{\circ} \mathrm{C}$. However, data at other temperatures is still lacking.

Here we report results of a study that has been under way for more than two years on the stability and evolution of phases in the CrMnFeCoNi HEA after prolonged anneals of 500 days at temperatures ranging from 500 to $900{ }^{\circ} \mathrm{C}$. Such long anneals make it likely that our microstructures are close to equilibrium.

\section{Experimental procedures}

Three cylindrical ingots (each $25.4 \mathrm{~mm}$ in diameter and $127 \mathrm{~mm}$ long) of the equiatomic CrMnFeCoNi high-entropy alloy were produced by arc melting and drop casting in pure Ar atmosphere. The starting materials and melting/casting procedures were similar to those described in an earlier publication [10]. After solidification, the ingots were cleaned in a solution of distilled water, hydrochloric acid and hydrogen peroxide, dried, individually encapsulated in evacuated quartz tubes, and homogenized for $48 \mathrm{~h}$ at $1200{ }^{\circ} \mathrm{C}$ to minimize any casting-related segregation.

\subsection{Annealing treatments}

After homogenization, the encapsulated ingots were placed in three nominally identical tube furnaces and annealed at 500,700 or $900{ }^{\circ} \mathrm{C}$ for 500 days. Control thermocouples $(K$ 
type) were positioned in the centers of each furnace and calibrated using a reference thermocouple before the annealing treatments began. The reference thermocouple was also used to measure the temperature profiles of the furnaces along their longitudinal axes after which the cylindrical ingots were placed in the roughly constant-temperature zones of the furnaces directly below the control thermocouple. After each heat treatment, microstructures were characterized by means of analytical and conventional SEM/TEM and APT, as described below.

\subsection{Scanning electron microscopy investigations}

For the SEM investigations, the ingot cross-sections were metallographically prepared by fine grinding followed by polishing on a vibratory polisher using first an alumina suspension (particle size $300 \mathrm{~nm}$ ) and then a colloidal silica suspension (particle size $50 \mathrm{~nm}$ ). The polished surfaces were analyzed in a FEI Quanta 650 microscope equipped with a field emission gun and an EDX detector. Imaging and chemical analyses were performed at an acceleration voltage of $20 \mathrm{kV}$. In addition to spot measurements, composition maps were acquired to check for chemical inhomogeneities. The collected data were evaluated using the software Genesis (EDAX, Mahwah, USA, Version 6.39). After an automatic background correction, the chemical compositions were determined using the $K$ lines for quantification.

\subsection{Transmission electron microscopy investigations}

Two different procedures were used for the TEM analysis. In the first method, TEM samples were prepared from slices $(\sim 1-\mathrm{mm}$ thick) cut from the annealed rods with a precision saw (Accutom-50, Struers, Ballerup, Denmark) equipped with a SiC cutting blade. The slices were ground on both sides to a thickness of $\sim 300 \mu \mathrm{m}$ using $\mathrm{SiC}$ paper with a grit size of P500 and then finer SiC paper (grit size P1000) to obtain foils of thickness $120 \mu \mathrm{m}$. Round discs with a diameter of $3 \mathrm{~mm}$ were punched out of these foils and electropolished in a double jet 
polishing system (TenuPol-5, Struers, Ballerup, Denmark) using an electrolyte consisting of $95 \%$ acetic acid and $5 \%$ perchloric acid at a temperature of $12{ }^{\circ} \mathrm{C}$ and an applied voltage of $30 \mathrm{~V}$. The microstructural investigations were performed in a Tecnai $G^{2}$ F20 SuperTwin microscope (FEI, Hillsboro, USA) or a JEOL JEM-2100 F microscope (Jeol, Tokyo, Japan) operated at $200 \mathrm{kV}$ and equipped with a X-Max80 EDS detector for X-ray microanalysis with an analytical system AZtec (Oxford Instruments, Abingdon, United Kingdom).

In the second method, a dual beam LYRA 3 XMU FEG/SEM-FIB microscope (TESCAN, Brno, Czech Republic) was used to machine TEM lamellae $\left(10 \times 10 \times 0.12 \mu \mathrm{m}^{3}\right)$ from grain-boundary regions of interest using a $\mathrm{Ga}^{+}$focused ion beam (FIB). A micromanipulator was used to lift out the lamella and weld it to a copper support designed for TEM sample holders. Bright field (BF) and dark field (DF) diffraction contrast as well as selected area diffraction (SAD) techniques were employed as part of conventional TEM investigations. Additionally, scanning TEM (STEM) experiments using BF and high-angle annular dark field (HAADF) detectors were also performed.

\subsection{Atom probe tomography investigations}

To investigate elemental distributions along the grain boundaries at near-atomic scale, APT measurements were performed using a local electrode atom probe (LEAP ${ }^{\mathrm{TM}} 3000 \mathrm{X}$ HR, Cameca Instruments, USA). The measurements were performed in voltage mode applying a voltage pulse fraction $\left(V_{\mathrm{p}} / V_{\mathrm{dc}}\right)$ of 0.15 at a repetition rate of $200 \mathrm{kHz}$ with the tip temperature maintained at $\sim 60 \mathrm{~K}$. APT tips were prepared by site-specific lift-out using a dual-beam focused ion beam (FEI Helios Nanolab 600i, USA) following the procedures described elsewhere $[33,34]$. In order to minimize $\mathrm{Ga}^{+}$beam damage, a low-energy $(5 \mathrm{kV})$ milling was performed at the final stage. APT data reconstruction and analyses were carried out using the IVAS 3.6.6 software provided by Cameca Instruments. 


\section{Results}

\subsection{As-homogenized state}

Figure 1a shows a representative low-magnification SEM image of the as-homogenized material. After homogenization, the CrMnFeCoNi HEA has coarse grains exceeding $1 \mathrm{~mm}$ in size. A few pores are visible in this and all other material states investigated; they appear to be casting porosity and/or holes left over from particles that fell out during the polishing process. Some intact particles are also visible, usually within the grains. Several of these particles were analyzed by EDX and were found to be rich in $\mathrm{Cr}, \mathrm{Mn}$ and $\mathrm{O}$, indicating that they are oxides, likely of type $\mathrm{Cr}_{2} \mathrm{MnO}_{4}$ (based on their EDX spectra). The presence of such inclusions is not surprising since they have been previously found in this alloy $[9,23,24]$. Some particles were found to be rich in $\mathrm{Mn}$ and $\mathrm{S}$, indicating that they are manganese sulfides, probably a result of S introduced as an impurity through the raw materials. Other than these inclusions (oxides and sulfides), no intermetallic particles ascribable just to the constituent elements of the HEA were observed after homogenization at $1200{ }^{\circ} \mathrm{C}$. Indeed, the EDX maps (Figs. 1b-f) of the area in Fig. 1a show that the constituent elements of the HEA are homogenously distributed with no evidence of segregation or clustering at the length scales of these images. Our present results are consistent with previous EDX results at similar length scales [24] and APT results at much finer scales $[27,32]$ which all show that the $\mathrm{CrMnFeCoNi} \mathrm{HEA} \mathrm{is} \mathrm{a} \mathrm{single-phase} \mathrm{solid} \mathrm{solution} \mathrm{after} \mathrm{homogenization} \mathrm{at} \mathrm{elevated}$ temperatures.

\subsection{After annealing at $900{ }^{\circ} \mathrm{C}$ for 500 days}

Figure 2a shows a representative SEM image of the microstructure after annealing for 500 days at $900{ }^{\circ} \mathrm{C}$ and Figs. 2 b-f show the corresponding EDX maps obtained from the area in Fig. 2a. These results are similar to those of the as-homogenized state (Fig. 1). Other than 
scattered Cr- and Mn-rich inclusions (oxides and sulfides), again no intermetallic particles were observed. The constituent elements are homogeneously distributed and the CrMnFeCoNi alloy remains a single-phase solid solution after 500 days at $900{ }^{\circ} \mathrm{C}$.

\subsection{After annealing at $700{ }^{\circ} \mathrm{C}$ for 500 days}

Figure 3a shows a representative SEM image of the microstructure after a 500-day anneal at $700{ }^{\circ} \mathrm{C}$ and Figs. $3 b-f$ show the corresponding EDX maps obtained from the area in Figs. 3a. Clearly, the microstructure is no longer single-phase. In the backscattered electron image (Fig. 3a), a second phase with brighter contrast can be seen on the grain boundaries (which are delineated with dashed lines as a guide to the eye). Similar precipitates were observed also at the intragranular voids or inclusions mentioned earlier. Their presence (almost exclusively) at these locations suggests heterogeneous nucleation. The precipitates are blocky, faceted and enriched in Cr (Fig. 3c). Thirteen of these particles, all of them located at grain boundaries, were analyzed by EDX (in the SEM) and their chemical compositions (at.\%) were found to be practically identical with small standard deviations: $\mathrm{Cr}=46.5 \pm 1.0, \mathrm{Fe}=16.6 \pm 0.2, \mathrm{Co}=17.6 \pm 0.1, \mathrm{Mn}=12.7 \pm 0.4$, and $\mathrm{Ni}=6.6 \pm 0.4$. Grain interior regions that were devoid of precipitates were also analyzed for comparison; none of those regions showed a significant deviation from the nominal equiatomic alloy composition within the uncertainty of EDX. These results are summarized in Table 1. Interestingly, the elemental maps (Figs. 3e,f) show a slight indication of Ni and Mn enrichment in the vicinity of the grain boundary; this could not be quantified and is therefore not included in Table 1 .

We initially tried to identify the crystal structure of the above Cr-rich grain-boundary phase with the help of conventionally thinned (twin-jet polished) TEM samples. However, due to the coarse grain size, grain boundaries were rarely present in the electron transparent regions. When we did come across a precipitate, SAD analysis was performed with a low- 
index crystal axis parallel to the incident electron beam. The experimental pattern was then compared to simulated patterns for low-index zone axes and good agreement was obtained between the experimental and simulated SAD patterns for a [101]-oriented Cr-Fe type $\sigma$ phase [35] indicating that our phase is likely a quinary variant of this topologically closepacked phase. However, the analyzed precipitate was situated in a relatively thick part of the TEM foil and thus the SAD data need to be interpreted with care.

In order to obtain further confirmation, another blocky grain boundary precipitate was selected for analysis and, together with the surrounding solid solution matrix, subjected to the FIB thinning procedure described in the experimental section. The resulting lamella with thickness $\leq 120 \mathrm{~nm}$ was suitable for rigorous SAD analysis, the results of which are presented in Fig. 4. The circles marked in the STEM image of Fig. 4a indicate the size and positions of the aperture used for the SAD experiments on the precipitate (1) and the HEA solid solution matrix (2). Corresponding SAD patterns are shown in Figs. 4b (precipitate) and 4c (matrix). To rationalize the experimental diffraction data, the electron diffraction intensities were simulated using JEMS software [36] assuming a [10-1] zone orientation for the tetragonal Crrich $\sigma$ phase precipitate (ICSD structure file no. 102747, tetragonal P42mnm, lattice parameters $a=0.87966 \mathrm{~nm}, c=0.45582 \mathrm{~nm}[37])$ and a [1-10] zone orientation for the FCC HEA matrix (cubic Fm-3m, lattice parameter $a=0.360 \mathrm{~nm}[25]$ ). There is good agreement between the JEMS data (red circles) and the experimental SAD patterns in Figs. 4b,c confirming our earlier conclusion that the precipitate is likely a quinary variant of the binary Cr-Fe $\sigma$ phase.

A striking feature of the STEM image in Fig. 4a is the high dislocation density in the HEA matrix. Since regions far from the matrix-particle interface were practically devoid of dislocations, one possibility is that these dislocations formed to accommodate the differential 
thermal contraction of the two phases during cool down from the annealing temperature. They could also have formed to accommodate volume misfits during growth of the $\sigma$ phase in the HEA matrix. Further work is required to clarify this issue.

Chemical compositions of the $\sigma$-phase precipitates observed in the FIB lamella were then analyzed using EDX. As an example, Figure 5a shows locations (circles 1 and 2) where EDX spectra were collected from the precipitate and matrix, respectively. The EDX spectra are shown in Fig. 5b ( $\sigma$ phase) and 5c (HEA matrix). Chromium is the strongest peak in the spectrum of the $\sigma$ phase, followed by smaller but almost equal $\mathrm{Fe}, \mathrm{Co}$ and $\mathrm{Mn}$ peaks and a rather weak Ni peak. In contrast, the peaks are nearly all equal in the spectrum from the matrix (location 2 , which is slightly more than $1 \mu \mathrm{m}$ away from the particle-matrix interface). Both spectra exhibit a small parasite $\mathrm{Cu}$ peak due to secondary scattering from the $\mathrm{Cu}$ support to which the lamella was welded. This extraneous peak was neglected during the subsequent quantification of the spectra to obtain chemical compositions. The average chemical compositions were calculated based on at least two independent EDX measurements in each of the two phases and the results are summarized in Table 1. As can be seen, the chemical compositions of the $\sigma$ phase obtained by EDX in the SEM and TEM are comparable.

The $\sigma$ phase was further analyzed using APT, as shown in Fig. 6. A relatively large $\sigma$ phase situated along a grain boundary was first identified and then material from the precipitate was lifted out. Three APT tips were obtained from the precipitate; for comparison, three APT tips were also obtained from the grain interior (HEA matrix). The elemental maps of the precipitate region (Fig. 6a) show that the distribution of constituent elements within the analyzed volume is homogenous with no indication of segregation or clustering at the atomic scale. Figure $6 \mathrm{~b}$ plots the concentrations of the different elements along the needle axis, within the 20-nm-diameter cylinder shown in the inset. As summarized in Table 1, the 
average composition (in at.\%) of the $\sigma$ phase is approximately $46 \mathrm{Cr}-12 \mathrm{Mn}-17 \mathrm{Fe}-18 \mathrm{Co}-7 \mathrm{Ni}$, which is comparable to those determined by EDX in the SEM and TEM. The composition of the grain (HEA matrix) is close to the nominal alloy composition and comparable to those determined by EDX.

\subsection{After annealing at $500{ }^{\circ} \mathrm{C}$ for 500 days}

Figure 7a shows a representative SEM image of the microstructure after a 500-day anneal at $500{ }^{\circ} \mathrm{C}$ and Figs. $7 b-f$ show the corresponding EDX maps obtained from the area in Fig. 7a. While the grain interiors are still almost entirely single-phase, an intricate chemical decomposition is observed along most grain boundaries (but not at coherent twin boundaries, which remain precipitate free). At low magnification, this decomposition makes the previously smooth grain boundaries ragged (convoluted). At higher magnification, a seam of small particles is evident on the grain boundaries, examples of which are shown in Fig. 7a. Given their small size $(\sim 1 \mu \mathrm{m})$, TEM was performed on FIB machined lamellae for detailed chemical and crystallographic analyses. Figure 8a is a representative HAADF image showing the decomposition of the HEA solid solution into a multitude of particles with complicated morphology and distribution. Based on EDX mapping of their chemical compositions, the results of which are shown in the overlay in Fig. 8b, the precipitates can be classified into three types: (i) a phase rich in $\mathrm{Ni}$ and $\mathrm{Mn}$ (yellow), (ii) a phase containing almost exclusively $\mathrm{Cr}$ (red) and (iii) a phase rich in Fe and Co (blue). Areas in Fig. 8b that are not color-coded represent either the untransformed HEA solid solution or regions where the EDX signal was insufficient for unambiguous classification. These individual phases were further investigated by SAD and EDX. Results of three representative SAD experiments are shown in Fig. 9. A portion of the color-coded map in Figure 8a is shown in Fig. 9a, where the three arrowed circles represent positions and sizes of the corresponding SAD apertures. Figures 9b-d 
illustrate very good match between the experimental SAD patterns and those simulated using JEMS calculations (the overlaid red circles). The calculations were performed using the following conditions: (i) for the pattern in Fig. 9b, [110] zone orientation of the tetragonal $\mathrm{L}_{0}$ phase NiMn (ICSD structure file no. 104916, tetragonal P4mmm, lattice parameters $a=$ $0.261 \mathrm{~nm}, c=0.349 \mathrm{~nm}$, [38]), (ii) for the pattern in Fig. 9c, [111] zone orientation of the BCC Cr phase (ICSD structure file no. 44731, cubic Im-3m, lattice parameter $a=0.28845$ $\mathrm{nm},[39]$ ) and (iii) for the pattern in Fig. 9d, [111] zone orientation of the cubic B2 phase FeCo (ICSD structure file no. 56273, cubic P $m-3 m$, lattice parameter $a=0.28572 \mathrm{~nm}$, [40]).

Figure 10 shows a portion of the color-coded map discussed before (Fig. 8) together with representative EDX spectra obtained from the three different phases. The arrowed circles in Fig. 10a indicate the locations where EDX spectra (Figs. 10b-d) were collected. One phase consists predominantly of $\mathrm{Cr}$, another is enriched in $\mathrm{Ni}$ and $\mathrm{Mn}$, and the third is enriched in Fe and Co. Four EDX point spectra were collected from each of these phases and the resulting average chemical compositions are summarized in Table 2. Although these phases are not unary or binary, for the sake of simplicity we will refer to them as $\mathrm{Cr}$, NiMn and FeCo in keeping with the crystal structures determined from our SAD experiments.

The NiMn precipitates were further analyzed using APT and Fig. 11a shows a representative needle containing these precipitates where the dark green regions (isoconcentration surfaces) represent contours of $\mathrm{Ni}$ concentration $\geq 30$ at.\%. Figure $11 \mathrm{~b}$ shows the statistical proximity histogram including all four precipitates and matrix visible in the analyzed volume. The composition of the matrix is close to the nominal alloy composition and comparable to the EDX results obtained from the matrix. The precipitate is enriched in $\mathrm{Ni}$ and $\mathrm{Mn}$ and depleted in the other elements and its composition is similar to that obtained by EDX in the TEM (Table 2). 


\section{Discussion}

Our microstructural analyses using multiple complementary techniques including, SEM, TEM, EDX, SAD, and APT have shown that the CrMnFeCoNi HEA produced by arc melting and drop casting is a homogenous single-phase solid solution after a 48 -h anneal at $1200{ }^{\circ} \mathrm{C}$. It retains its single-phase solid solution state after a prolonged anneal of 500 days at $900{ }^{\circ} \mathrm{C}$. However, it decomposes into metallic and intermetallic phases at lower temperatures. After 500 days at $700{ }^{\circ} \mathrm{C}$, relatively large blocky precipitates were observed at heterogeneous sites, mainly grain boundaries, but also at intragranular pores and inclusions. Analysis of the SAD patterns showed that their crystal structure was the same as that of the tetragonal $\mathrm{Cr}-\mathrm{Fe}$ $\sigma$ phase. EDX and APT analysis showed that although they were rich in $\mathrm{Cr}(\sim 47$ at.\%), they contained all the constituent elements of the HEA (Table 1). Therefore, our $\sigma$ phase appears to be a quinary variant of the binary $\sigma$ phase, which may be rationalized as follows: 1) Cr is known to be a strong $\sigma$-phase former. The $\sigma$ phase has been shown to form in all binary systems of the type $\mathrm{Cr}-\mathrm{X}$ where $\mathrm{X}=\mathrm{Co}, \mathrm{Fe}, \mathrm{Mn}$ and $\mathrm{Ni}[37,41-43]$. It is thus conceivable that a quinary $\sigma$ phase containing these five elements can also form. 2) Despite being stable over different compositional ranges, the lattice parameters of the reported binary $\mathrm{Cr}-\mathrm{X} \sigma$ phases are very similar. Additionally, these elements all have similar atomic radii [44]. Therefore, one might reasonably expect these atoms to substitute for each other without making the $\sigma$ phase unstable. 3) For the chemical composition of the precipitates found in the present study, the $\sigma$ phase is predicted to be the stable structure on the basis of atomic size difference and electronic $d$-band filling [45].

After 500 days at $500{ }^{\circ} \mathrm{C}$, a more complex decomposition takes place and three distinct phases are observed: a phase rich in $\mathrm{Ni}$ and $\mathrm{Mn}$, another that is predominantly $\mathrm{Cr}$, and a third that is enriched in Fe and Co. To establish their crystallography, JEMS simulations were 
performed assuming the tetragonal $\mathrm{L} 1_{0}$ crystal structure for the NiMn phase, $\mathrm{BCC}$ for the $\mathrm{Cr}$ rich phase, and B2 for the FeCo phase. Superlattice reflections were clearly visible in the experimental SAD pattern of the NiMn phase indicative of atomic ordering within the phase. Additionally, in the paper by Egorushkin et al. [38] from which the crystal structure data were taken, the NiMn phase is reported to be stable only below $665^{\circ} \mathrm{C}$ which is consistent with our results. The crystal structure of the Cr-rich phase was virtually indistinguishable from that of pure $\mathrm{BCC} \mathrm{Cr}$ [46] for a [111] zone axis. Finally, the B2 FeCo phase [40] forms near the equiatomic composition in the binary Fe-Co system below temperatures of approximately $730{ }^{\circ} \mathrm{C}$ [47], which is consistent with both the composition and temperature of our FeCo phase. Comparison of the experimental SAD patterns with the JEMS simulations showed excellent agreement between the experimental and simulated patterns of all three phases.

Our $700{ }^{\circ} \mathrm{C}$ results are in good agreement with the recent results of Pickering et al. [24] who observed blocky grain-boundary particles with shapes similar to those seen by us here. Based on SAD analysis they also concluded that the crystal structure of the precipitates was consistent with the $\sigma$ phase. Moreover, their lattice parameters were close to those deduced here. As for its chemical composition, Pickering et al. [24] reported that "it was significantly enriched in $\mathrm{Cr}$, and also contained some $\mathrm{Mn}, \mathrm{Fe}$, and $\mathrm{Co}$, but very little Ni." This is consistent with what we found in the present study, but a more detailed comparison is not possible since they did not provide a chemical composition for their $\sigma$ phase. In the study of Pickering et al. [24], the $\sigma$ phase appeared in samples annealed for relatively short times (500 hours) compared to the 500-day anneals of this study. An open question is whether the composition of the $\sigma$ phase evolves with time between 500 hours and 500 days or whether it is already close to its equilibrium composition at shorter times. 
Our $500{ }^{\circ} \mathrm{C}$ results can only be compared with the $450{ }^{\circ} \mathrm{C}$ results of Schuh et al. [27] but even then only qualitatively since they did not unambiguously identify the crystal structures of the phases observed. Chemically, however, our three phases appear to be similar to, if not the same as, what they reported. A major difference is that Schuh et al. [27] observed the NiMn and Cr-rich phases after times as short as 5 minutes and the FeCo phase after $15 \mathrm{~h}$. Here we looked at samples that had been annealed for 500 days. Since shorter anneals were not investigated in this study, it is not possible to say whether these phases would appear in our material more quickly, or whether a starting nanocrystalline state produced by HPT inherently results in significantly faster precipitation kinetics. If the latter is the case, the question then becomes whether it is the result of grain boundaries offering faster diffusion pathways and/or additional nucleation sites, or whether the HPT state has high internal energy that provides additional driving force for precipitation. These are all interesting aspects that need to be investigated in future studies. Regardless of the formation kinetics, however, it has been shown that the precipitates have the potential to severely embrittle the CrMnFeCoNi HEA [27].

A noteworthy aspect of the present study is that after 500 days at $900{ }^{\circ} \mathrm{C}$, the CrMnFeCoNi HEA remained a single-phase solid solution. Consistent with this, when Schuh et al. [27] annealed their four-phase material (HEA matrix containing NiMn, Cr, and FeCo precipitates) at $800^{\circ} \mathrm{C}$ for 1 hour, they obtained a single-phase solid solution (i.e., all the precipitates dissolved back into the HEA matrix). Together, these results indicate that the FCC solid solution state is stable above approximately $800^{\circ} \mathrm{C}$ and that at lower temperatures several different precipitates form depending on time and temperature. Considering all the available data, it is possible to envisage a schematic TTT diagram, such as the one shown in Fig. 12, for the CrMnFeCoNi HEA. Of course, additional work is needed to quantify and 
understand the various factors (grain size, undercooling, etc.) that affect the phase transformation kinetics.

Meanwhile, it is now clear that there is only limited entropic stabilization of the solid solution state in the CrMnFeCoNi HEA. Our experimental results may be compared with multinary phase diagrams created from the constituent (known) binaries [48]. In the case of the $\mathrm{CrMnFeCoNi}$ quinary, the prediction was that a FCC solid solution would be stable above $600{ }^{\circ} \mathrm{C}$, which would decompose into a BCC and FCC phase at lower temperatures. The experimental results are at odds with this prediction indicating the need for further refinement of thermodynamic models.

Our results should motivate the investigation of possible phase transformations in other HEAs that are currently thought of as being single phase but may decompose if annealed at the right temperature-time combination. Information about phase instabilities will be important in alloys that are being considered for applications in sensitive temperature regimes and where potential embrittlement by intermetallic precipitates is a concern.

\section{Summary and Conclusions}

The microstructural evolution of an equiatomic, single-phase, solid solution highentropy alloy, $\mathrm{CrMnFeCoNi}$, was investigated after 500-day anneals at temperatures of 500, 700 and $900{ }^{\circ} \mathrm{C}$. These long annealing times were chosen to promote thermodynamic equilibration of the microstructure. The annealed microstructures were characterized over several length scales using scanning and transmission electron microscopy along with energy-dispersive X-ray spectroscopy and atom probe tomography. The results can be summarized as follows. 
(1) After homogenization for 48 hours at $1200^{\circ} \mathrm{C}$, the equiatomic CrMnFeCoNi highentropy alloy is a single-phase solid solution. It remains a single-phase solid solution after 500 days at $900{ }^{\circ} \mathrm{C}$. Results obtained in an earlier study [27] indicate that the solid solution state is stable also at $\sim 800^{\circ} \mathrm{C}$. Together, these observations suggest that entropy probably stabilizes the FCC solid solution in $\mathrm{CrMnFeCoNi}$ at temperatures higher than $\sim 800^{\circ} \mathrm{C}$. At lower temperatures, the solid solution becomes unstable and several secondary phases precipitate, probably because of their enthalpies.

(2) A Cr-rich precipitate is observed after annealing for 500 days at $700{ }^{\circ} \mathrm{C}$ and is present almost exclusively at grain boundaries and inclusions/pores indicating that its nucleation is likely heterogeneous. Its chemical composition (in at.\%) is approximately 46.5Cr-16.6Fe-17.6Co-12.7Mn-6.6Ni and its crystal structure is that of the Cr-Fe type $\sigma$ phase. Therefore, this secondary phase is likely a quinary variant of the binary $\sigma$ phase.

(3) A complex chemical decomposition takes place at the grain boundaries after 500 days at $500{ }^{\circ} \mathrm{C}$. Three distinctly different phases were identified: a BCC phase that consists predominantly of $\mathrm{Cr}\left(\sim 86\right.$ at.\%), a tetragonal phase ( $\mathrm{L}_{0}$ structure) that is rich in $\mathrm{Ni}$ and Mn ( $\sim 55$ and 37 at.\%, respectively), and an ordered cubic phase (B2 structure) that is rich in $\mathrm{Fe}$ and $\mathrm{Co}(\sim 46$ at. $\%$ of each).

(4) Preliminary attempts have been made in the literature to create phase diagrams for the CrMnFeCoNi HEA from its known constituent binaries. However, their predictions do not agree with our experimental results indicating that current thermodynamic databases and models need to be extended and refined to better handle complex solid solutions. Further work is also needed to experimentally determine the full temperature-timetransformation (TTT) characteristics of this and other HEAs.

(5) The limited entropic stabilization of the prototypical FCC high-entropy alloy, CrMnFeCoNi, highlights the need to carefully evaluate the stability of other HEAs that 
have not been extensively investigated but are nevertheless believed to be stable solid solutions. Phase decompositions and their associated effects on mechanical properties, although unlikely to be important at cryogenic temperatures (because of slow diffusion), certainly need to be taken into account for elevated temperature applications since potentially embrittling second phases could precipitate during service.

\section{Acknowledgments}

The alloys were produced and heat-treated when F.O and E.P.G were at the Oak Ridge National Laboratory under sponsorship of the U.S. Department of Energy, Office of Basic Energy Sciences, Materials Sciences and Engineering Division. F.O. also received funding from the Alexander von Humboldt Foundation through a Feodor Lynen Research Fellowship and wishes to thank Dr. H. Bei (ORNL) for removing some of specimens from the furnace after the anneals and shipping them to Germany. A.D. and M.K. received financial support from the Czech Science Foundation under contract no. 14-22834S. G.E., D.R. and E.P.G. acknowledge funding from the German Research Association (DFG) through projects A1, A4 and B5/B7, respectively, of the collaborative research program SFB/TR 103.

\section{References}

[1] B. Cantor, I.T.H. Chang, P. Knight, A.J.B. Vincent, Microstructural development in equiatomic multicomponent alloys, Mater. Sci. Eng. A 375-377 (2004) 213-218.

[2] J.-W. Yeh, S.-K. Chen, S.-J. Lin, J.-Y. Gan, T.-S. Chin, T.-T. Shun, C.-H. Tsau, S.-Y. Chang, Nanostructured high-entropy alloys with multiple principal elements: Novel alloy design concepts and outcomes, Adv. Eng. Mater. 6 (2004) 299-303. 
[3] M.S. Lucas, L. Mauger, J.A. Muñoz, Y. Xiao, A.O. Sheets, S.L. Semiatin, J. Horwath, Z. Turgut, Magnetic and vibrational properties of high-entropy alloys, J. Appl. Phys. 109 (2011) $07 E 307$.

[4] O.N. Senkov, G.B. Wilks, J.M. Scott, D.B. Miracle, Mechanical properties of $\mathrm{Nb}_{25} \mathrm{Mo}_{25} \mathrm{Ta}_{25} \mathrm{~W}_{25}$ and $\mathrm{V}_{20} \mathrm{Nb}_{20} \mathrm{Mo}_{20} \mathrm{Ta}_{20} \mathrm{~W}_{20}$ refractory high-entropy alloys, Intermetallics 19 (2011) 698-706.

[5] O.N. Senkov, J.M. Scott, S.V. Senkova, D.B. Miracle, C.F. Woodward, Microstructure and room temperature properties of a high-entropy TaNbHfZrTi alloy, J. Alloys Compd. 509 (2011) 6043-6048.

[6] M.S. Lucas, G.B. Wilks, L. Mauger, J.A. Muñoz, O.N. Senkov, Absence of long-range chemical ordering in equimolar FeCoCrNi, Appl. Phys. Lett. 100 (2012) 251907.

[7] W.H. Liu, Y. Wu, J.Y. He, T.G. Nieh, Z.P. Lu, Grain growth and the Hall-Petch relationship in a high-entropy FeCrNiCoMn alloy, Scr. Mater. 68 (2013) 526-529. [8] F. Otto, Y. Yang, H. Bei, E.P. George, Relative effects of enthalpy and entropy on the phase stability of equiatomic high-entropy alloys, Acta Mater. 61 (2013) 2628-2638.

[9] A. Gali, E.P. George, Tensile properties of high- and medium-entropy alloys, Intermetallics 39 (2013) 74-78.

[10] F. Otto, A. Dlouhý, Ch. Somsen, H. Bei, G. Eggeler, E.P. George, The influences of temperature and microstructure on the tensile properties of a $\mathrm{CoCrFeMnNi}$ high-entropy alloy, Acta Mater. 61 (2013) 5743-5755. 
[11] P.P. Bhattacharjee, G.D. Sathiaraj, M. Zaid, J.R. Gatti, C. Lee, C.-W. Tsai, J.-W. Yeh, Microstructure and texture evolution during annealing of equiatomic $\mathrm{CoCrFeMnNi}$ highentropy alloy, J. Alloys Compd. 587 (2014) 544-552.

[12] M.J. Yao, K.G. Pradeep, C.C. Tasan, D. Raabe. A novel, single phase, non-equiatomic FeMnNiCoCr high-entropy alloy with exceptional phase stability and tensile ductility, Scripta Materialia 72-73 (2014) 5-8.

[13] Y. Zou, S. Maiti, W. Steurer, R. Spolenak, Size-dependent plasticity in an $\mathrm{Nb}_{25} \mathrm{Mo}_{25} \mathrm{Ta}_{25} \mathrm{~W}_{25}$ refractory high-entropy alloy, Acta Mater. 65 (2014) 85-97.

[14] C.C. Tasan, Y. Deng, K.G. Pradeep, M.J. Yao, H. Springer, D. Raabe. Composition dependence of phase stability, deformation mechanisms, and mechanical properties of the CoCrFeMnNi high-entropy alloy system, JOM 66 (2014) 1993-2001.

[15] M. Feuerbacher, M. Heidelmann, C. Thomas, Hexagonal high-entropy alloys, Mater. Res. Lett. 3 (2015) 1-6.

[16] Y. Deng, C.C. Tasan, K.G. Pradeep, H. Springer, A. Kostka, D. Raabe. Design of a twinning-induced plasticity high entropy alloy, Acta Materialia 94 (2015) 124-133.

[17] D. Ma, M. Yao, K.G. Pradeep, C.C. Tasan, H. Springer, D. Raabe. Phase stability of non-equiatomic CoCrFeMnNi high entropy alloys, Acta Mater. 98 (2015) 288-296.

[18] J.-Ph. Couzinié, L. Lilensten, Y. Champion, G. Dirras, L. Perrière, I. Guillot, On the room temperature deformation mechanisms of a TiZrHfNbTa refractory high-entropy alloy, Mater. Sci. Eng. A 645 (2015) 255-263. 
[19] D. Ma, B. Grabowski, F. Kormann, J. Neugebauer, D. Raabe. Ab initio thermodynamics of the CoCrFeMnNi high entropy alloy: Importance of entropy contributions beyond the configurational one, Acta Mater. 100 (2015) 90-97.

[20] D. Raabe, C.C. Tasan, H. Springer, M. Bausch. From High-Entropy Alloys to HighEntropy Steels, Steel Research International 86 (2015) 1127-1138.

[21] K.G. Pradeep, C.C. Tasan, M.J. Yao, Y. Deng, H. Springer, D. Raabe. Non-equiatomic high entropy alloys: Approach towards rapid alloy screening and property- oriented design, Mater. Sci. Eng. A 648 (2015) 183-192.

[22] Z. Li, K.G. Pradeep, Y. Deng, D. Raabe, C.C. Tasan, Metastable high entropy dual phase alloys overcome the strength ductility trade off, Nature (2016), accepted for publication.

[23] F. Otto, N.L. Hanold, E.P. George, Microstructural evolution after thermomechanical processing in an equiatomic, single-phase CoCrFeMnNi high-entropy alloy with special focus on twin boundaries, Intermetallics 54 (2014) 39-48.

[24] E.J. Pickering, R. Muñoz-Moreno, H.J. Stone, N.G. Jones, Precipitation in the equiatomic high-entropy alloy CrMnFeCoNi, Scripta Mater. 113 (2016) 106-109.

[25] G. Laplanche, P. Gadaud, O. Horst, F. Otto, G. Eggeler, E.P. George, Temperature dependencies of the elastic moduli and thermal expansion coefficient of an equiatomic, single-phase CoCrFeMnNi high-entropy alloy, J. Alloys Compd. 623 (2015) 348-353.

[26] N. Stepanov, M. Tikhonovsky, N. Yurchenko, D. Zyabkin, M. Klimova, S. Zherebtsov, A. Efimov, G. Salishchev, Effect of cryo-deformation on structure and properties of CoCrFeMnNi high-entropy alloy, Intermetallics 59 (2015) 8-17. 
[27] B. Schuh, F. Mendez-Martin, B. Völker, E.P. George, H. Clemens, R. Pippan, A.

Hohenwarter, Mechanical properties, microstructure and thermal stability of a nanocrystalline CoCrFeMnNi high-entropy alloy after severe plastic deformation, Acta Mater. 96 (2015) $258-268$.

[28] B. Gludovatz, A. Hohenwarter, D. Catoor, E.H. Chang, E.P. George, R.O. Ritchie, A fracture-resistant high-entropy alloy for cryogenic applications, Science 345 (2014) 11531158.

[29] C. Zhu, Z.P. Lu, T.G. Nieh, Incipient plasticity and dislocation nucleation of FeCoCrNiMn high-entropy alloy, Acta Mater. 61 (2013) 2993-3001.

[30] G.A. Salishchev, M.A. Tikhonovsky, D.G. Shaysultanov, N.D. Stepanov, A.V. Kuznetsov, I.V. Kolodiy, A.S. Tortika, O.N. Senkov, Effect of Mn and V on structure and mechanical properties of high-entropy alloys based on CoCrFeNi system, J. Alloys Compd. $591(2014) 11-21$.

[31] N.D. Stepanov, D.G. Shaysultanov, N.Y. Yurchenko, S.V. Zherebtsov, A.N. Ladygin, G.A. Salishchev, M.A. Tikhonovsky, High temperature deformation behavior and dynamic recrystallization in CoCrFeMnNi high entropy alloy, Mater. Sci. Eng. A 636 (2015) 188-195.

[32] M. Laurent-Brocq, A. Akhatova, L. Perrière, S. Chebini, X. Sauvage, E. Leroy, Y. Champion, Insights into the phase diagram of the CrMnFeCoNi high entropy alloy, Acta Mater. 88 (2015) 355-365.

[33] S. Mandal, K.G. Pradeep, S. Zaefferer, D. Raabe. A novel approach to measure grain boundary segregation in bulk polycrystalline materials in dependence of the boundaries' five rotational degrees of freedom, Scr. Mater. 81 (2014) 16-19. 
[34] H. Zhang, K.G. Pradeep, S. Mandal, D. Ponge, H. Springer, D. Raabe. Dynamic straininduced transformation: An atomic scale investigation, Scr. Mater. 109 (2015) 23-27.

[35] K.H.J. Buschow, P.G. van Engen, R. Jongebreur, Magneto-optical properties of metallic ferromagnetic materials, J. Magn. Magn. Mater. 38 (1983) 1-22.

[36] P. A. Stadelmann, JEMS - Electron Microscopy Software, version 4.2231U2014, copyright P. Stadelmann 1999-2014, 2014, JEMS-SAAS, Switzerland.

[37] H.L. Yakel, Atom distributions in sigma phases. I. Fe and $\mathrm{Cr}$ atom distributions in a binary sigma phase equilibrated at 1063, 1013 and 923 K, Acta Cryst. B39 (1983) 20-28.

[38] V.E. Egorushkin, S.N. Kulkov, S.E. Kulkova, Electronic structure and the theory of phase transformations in NiMn, Physica B 123 (1983) 61-68.

[39] M.E. Straumanis, C.C. Weng, The absorption and refraction corrections and the lattice constant of chromium, Am. Mineral. 41 (1956) 437-448.

[40] P. Bayliss, Revised unit-cell dimensions, space group, and chemical formula of some metallic minerals, Can. Mineral. 28 (1990) 751-755.

[41] G.J. Dickins, A.M.B. Douglas, W.H. Taylor, The crystal structure of the Co-Cr $\sigma$ phase, Acta Cryst. 9 (1956) 297-303.

[42] E. Lugscheider, P. Ettmayer, Hochtemperatur-röntgenographische Untersuchungen an manganreichen Mangan-Vanadin und Mangan-Chrom-Legierungen, Monatsh. Chem. 102 (1971) 1234-1244.

[43] N. Yukawa, M. Hida, T. Imura, M. Kawamura, Y. Mizuno, Structure of chromium-rich Cr-Ni, Cr-Fe, Cr-Co, and Cr-Ni-Fe alloy particles made by evaporation in argon, Metall. Trans. 3 (1972) 887-895. 
[44] R.J.D. Tilley, Understanding Solids: The Science of Materials, first ed., Wiley, Hoboken, 2004.

[45] B. Seiser, R. Drautz, D.G. Pettifor, TCP phase predictions in Ni-based superalloys: Structure maps revisited, Acta Mater. 59 (2011) 749-763.

[46] L.M. Baklanova, L.N. Larikov, A.I. Ustinov, K.V. Chuistov, Crystal structure of chromium below Néel temperature, Dokl. Akad. Nauk SSSR 237 (1977) 79-81.

[47] Y.I. Ustinovshikov, B.E. Pushkarev, I.V. Sapegina, Phase separation and ordering in the Fe-Co system, Inorg. Mater. 42 (2006) 354-359.

[48] F. Zhang, C. Zhang, S.L. Chen, J. Zhu, W.S. Cao, U.R. Kattner, An understanding of high entropy alloys from phase diagram calculations, CALPHAD 45 (2014) 1-10.

Table 1: Average chemical compositions (at.\%) and standard deviations of grain-boundary precipitates ( $\sigma$ phase) present in $\mathrm{CrMnFeCoNi}$ after 500 days at $700^{\circ} \mathrm{C}$. Grain interiors were also analyzed and their compositions are close to the nominal HEA composition.

\begin{tabular}{ccccccc}
\hline Method & Location & $\mathrm{Cr}$ & $\mathrm{Mn}$ & $\mathrm{Fe}$ & $\mathrm{Co}$ & $\mathrm{Ni}$ \\
\hline \multirow{2}{*}{ TEM-EDX } & Precipitate & $46.5 \pm 1.0$ & $12.7 \pm 0.4$ & $16.6 \pm 0.2$ & $17.6 \pm 0.1$ & $6.6 \pm 0.4$ \\
& Grain & 20.0 & 19.6 & 19.9 & 20.1 & 20.4 \\
\hline \multirow{2}{*}{ TEM-EDX } & Precipitate & $46.8 \pm 0.5$ & $12.5 \pm 0.3$ & $16.9 \pm 0.2$ & $18.1 \pm 0.2$ & $5.7 \pm 0.2$ \\
& Grain & $18.5 \pm 1.0$ & $19.8 \pm 0.2$ & $20.2 \pm 0.0$ & $20.8 \pm 0.4$ & $20.7 \pm 0.4$ \\
\hline \multirow{2}{*}{ APT } & Precipitate & $46.0 \pm 0.6$ & $12.3 \pm 0.4$ & $17.1 \pm 0.5$ & $18.2 \pm 0.5$ & $6.7 \pm 0.3$ \\
& Grain & $18.7 \pm 0.5$ & $19.4 \pm 0.5$ & $19.8 \pm 0.5$ & $20.4 \pm 0.5$ & $21.5 \pm 0.5$ \\
\hline
\end{tabular}


Table 2: Average chemical compositions (at.\%) and standard deviations of phases present in $\mathrm{CrMnFeCoNi}$ after 500 days at $500^{\circ} \mathrm{C}$.

\begin{tabular}{ccccccc}
\hline Method & Phase & $\mathrm{Cr}$ & $\mathrm{Mn}$ & $\mathrm{Fe}$ & $\mathrm{Co}$ & $\mathrm{Ni}$ \\
\hline \multirow{4}{*}{ TEM-EDX } & $\mathrm{L} 1_{0} \mathrm{NiMn}$ & $1.9 \pm 0.6$ & $37.4 \pm 6.6$ & $2.2 \pm 0.8$ & $3.6 \pm 1.0$ & $54.9 \pm 8.9$ \\
& $\mathrm{BCC} \mathrm{Cr}$ & $86.3 \pm 3.6$ & $4.3 \pm 3.1$ & $5.2 \pm 2.6$ & $3.6 \pm 2.8$ & $0.6 \pm 1.0$ \\
& $\mathrm{~B} 2 \mathrm{FeCo}$ & $2.0 \pm 2.1$ & $5.5 \pm 2.1$ & $46.0 \pm 3.2$ & $45.9 \pm 2.2$ & $0.6 \pm 0.9$ \\
\hline APT & $\mathrm{L} 1_{0} \mathrm{NiMn}$ & $2.3 \pm 0.3$ & $42 \pm 0.9$ & $1.2 \pm 0.5$ & $3.9 \pm 0.3$ & $50.6 \pm 1$ \\
\hline
\end{tabular}

\section{Figure Captions}

Fig. 1 Microstructure of the CrMnFeCoNi HEA after homogenization at $1200{ }^{\circ} \mathrm{C}$ for $48 \mathrm{~h}$. Representative BSE image showing the relatively coarse grains (a) and elemental EDX maps showing the uniform distribution of $\mathrm{Co}(\mathrm{b}), \mathrm{Cr}(\mathrm{c}), \mathrm{Fe}(\mathrm{d}), \mathrm{Mn}(\mathrm{e})$, and $\mathrm{Ni}(\mathrm{f})$ in the area shown in (a). The scattered dark particles in (a) are oxide and sulfide inclusions.

Fig. 2 Microstructure of the CrMnFeCoNi HEA after a 500-day anneal at $900{ }^{\circ} \mathrm{C}$. Representative BSE image showing the relatively coarse grains (a) and elemental EDX maps showing the uniform distribution of $\mathrm{Co}(\mathrm{b}), \mathrm{Cr}(\mathrm{c}), \mathrm{Fe}(\mathrm{d}), \mathrm{Mn}(\mathrm{e})$, and $\mathrm{Ni}(\mathrm{f})$ in the area shown in (a). The scattered dark particles in (a) are oxide and sulfide inclusions.

Fig. 3 Microstructure of the $\mathrm{CrMnFeCoNi}$ HEA after a 500-day anneal at $700{ }^{\circ} \mathrm{C}$.

(a) Representative BSE image showing the presence of blocky faceted precipitates on a grain boundary. (b-f) Elemental EDX maps showing significant enrichment of $\mathrm{Cr}$ in the precipitates (relative to its concentration in the HEA) and depletion of all other elements. The dashed line delineating the grain boundary in (a) was added as a guide to the eye. There appears to be a slight enrichment of Mn and Ni near the grain boundary in (e) and (f). 
Fig. 4 STEM and SAD analysis of a FIB lamella extracted from the CrMnFeCoNi alloy after a $700{ }^{\circ} \mathrm{C}$ anneal for 500 days. (a) STEM BF image showing part of a grain-boundary precipitate (left) and the surrounding $\mathrm{CrMnFeCoNi}$ matrix (right). Circles 1 and 2 indicate the locations and sizes of the aperture used for the SAD experiments on the precipitate and matrix, respectively. (b) and (c) show SAD images for the precipitate and matrix, respectively, on which the simulated diffraction patterns (red circles) are superimposed.

Fig. 5 STEM and EDX analysis of a FIB lamella extracted from the CrMnFeCoNi alloy after a $700{ }^{\circ} \mathrm{C}$ anneal for 500 days. (a) STEM BF image showing part of a grain-boundary precipitate (left) and the surrounding $\mathrm{CrMnFeCoNi}$ matrix (right). EDX was performed at the locations marked by circles 1 and 2 (precipitate and matrix, respectively). Figures (b) and (c) display the corresponding EDX spectra.

Fig. 6 APT analysis of grain-boundary precipitate in the CrMnFeCoNi HEA after a 500-day anneal at $700{ }^{\circ} \mathrm{C}$. (a) Elemental maps showing homogeneous distribution of all elements. (b) Concentrations of the elements comprising the precipitate plotted along the long axis of the blue cylinder shown in the inset (diameter, $20 \mathrm{~nm}$ ) with $0.5 \mathrm{~nm}$ bin width.

Fig. 7 Microstructure of the CrMnFeCoNi HEA after a 500-day anneal at $500{ }^{\circ} \mathrm{C}$. Representative BSE image showing multiple precipitates on a grain boundary (a) and elemental EDX maps showing the distribution of $\mathrm{Co}(\mathrm{b}), \mathrm{Cr}(\mathrm{c}), \mathrm{Fe}(\mathrm{d}), \mathrm{Mn}(\mathrm{e})$, and $\mathrm{Ni}(\mathrm{f})$ in the area shown in (a).

Fig. 8 STEM and EDX analysis of a FIB lamella extracted from the CrMnFeCoNi alloy after a $500{ }^{\circ} \mathrm{C}$ anneal for 500 days. (a) STEM BF contrast reveals the presence of several secondary precipitates on a grain boundary of the CrMnFeCoNi matrix. (b) EDX maps superimposed on the image in (a) show that the precipitates have three distinct chemical compositions. 
Fig. 9 SAD analysis of a portion of the map shown in Figs. 8b. (a) Arrowed circles indicate the sizes and locations of the apertures used for SAD on the precipitates (NiMn, $\mathrm{Cr}$, and FeCo). (b), (c) and (d) present the corresponding SAD images on which the simulated diffraction patterns (red circles) are superimposed.

Fig. 10 EDX analysis of a portion of the map shown in Figs. 8b. (a) Arrowed circles indicate electron beam positions where EDX point spectra were acquired from the three different types of precipitate. (b), (c) and (d) show the corresponding EDX spectra.

Fig. 11 (a) APT Ni map showing the distribution of the NiMn precipitates in the CrMnFeCoNi HEA after a 500-day anneal at $500{ }^{\circ} \mathrm{C}$ using $\sim 30$ at. $\%$ iso-concentration surfaces, and (b) statistical proximity histogram (0.5 $\mathrm{nm}$ bin width) including the four precipitates and matrix region visible in (a) showing near-equiatomic composition in the matrix and $\mathrm{Ni}+\mathrm{Mn}$ enrichment in the precipitate.

Fig. 12 Schematic (hypothesized) TTT curve for the CrMnFeCoNi high-entropy alloy. 
Fig. 1

(a)

(b)

$200 \mu \mathrm{m}$

(c)

$\mathrm{Cr}$

(d)

(e)

$\mathrm{Fe}$

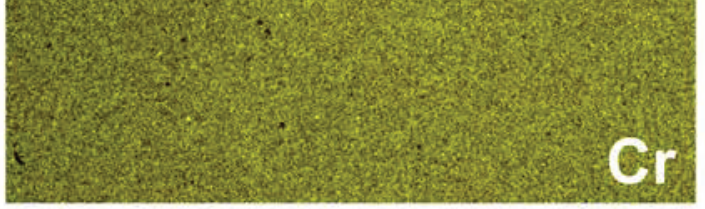


Fig. 2

(a)

(b)

-

$\theta$

$20 \mu \mathrm{m}$

Co

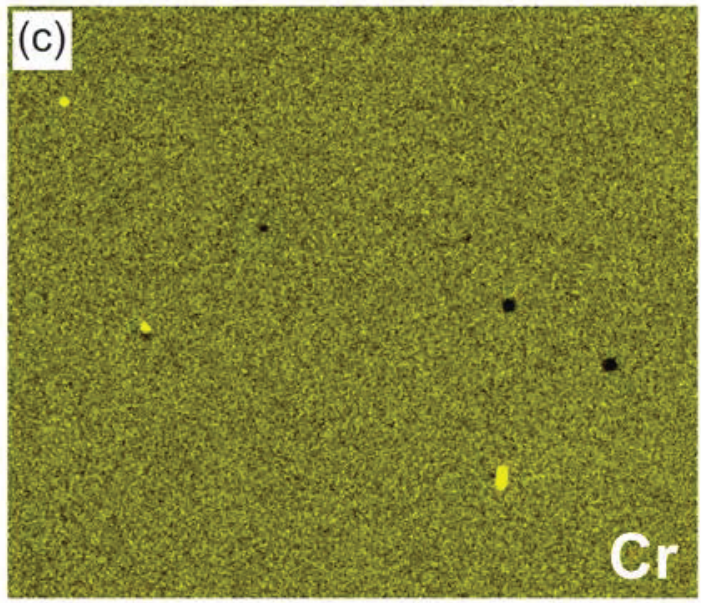

(d)

(e)

(f)

$\mathrm{Fe}$ 
Fig. 3

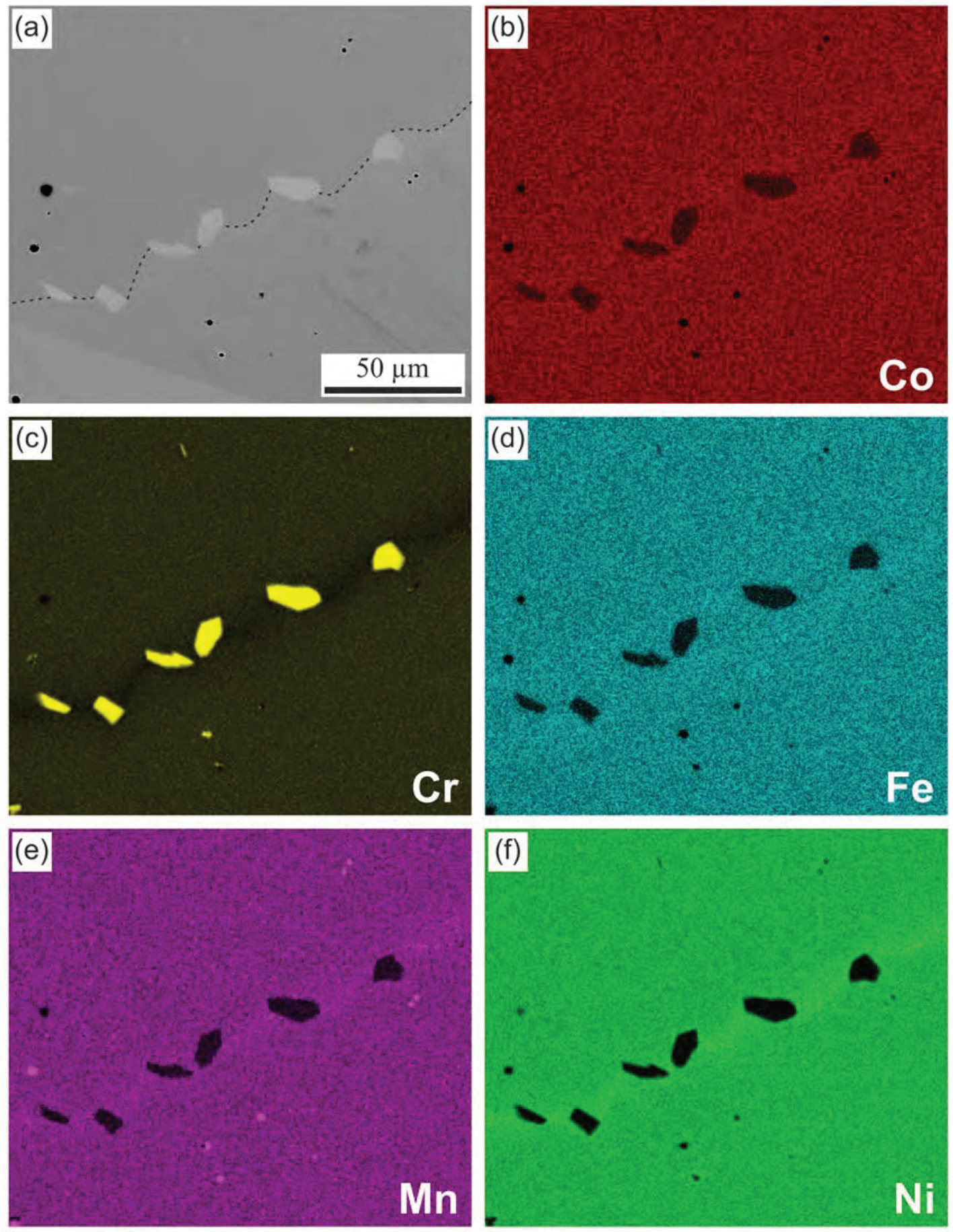


Fig. 4
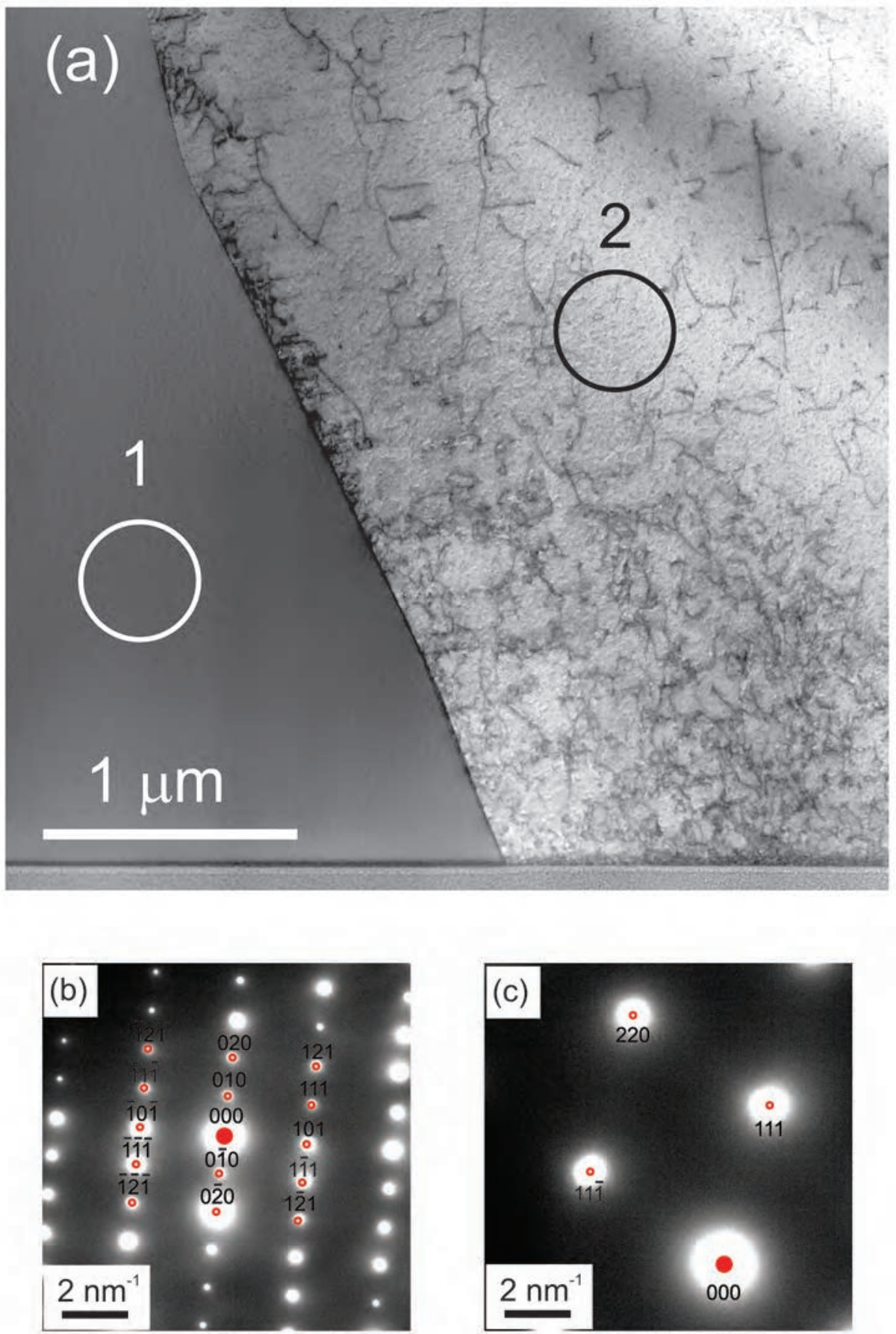
Fig. 5
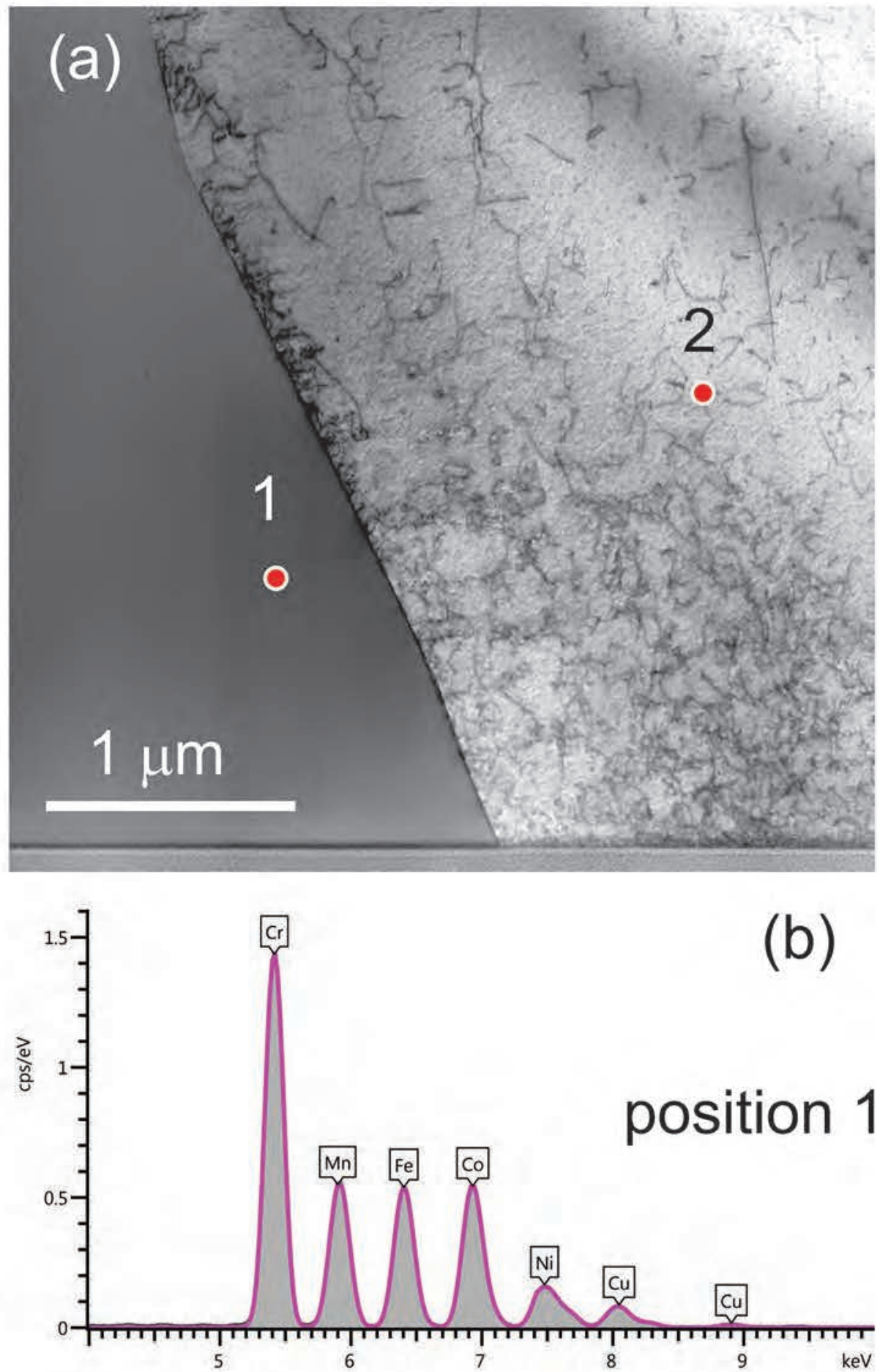

$\mathrm{Mn} \mathrm{Fe}$

position 1

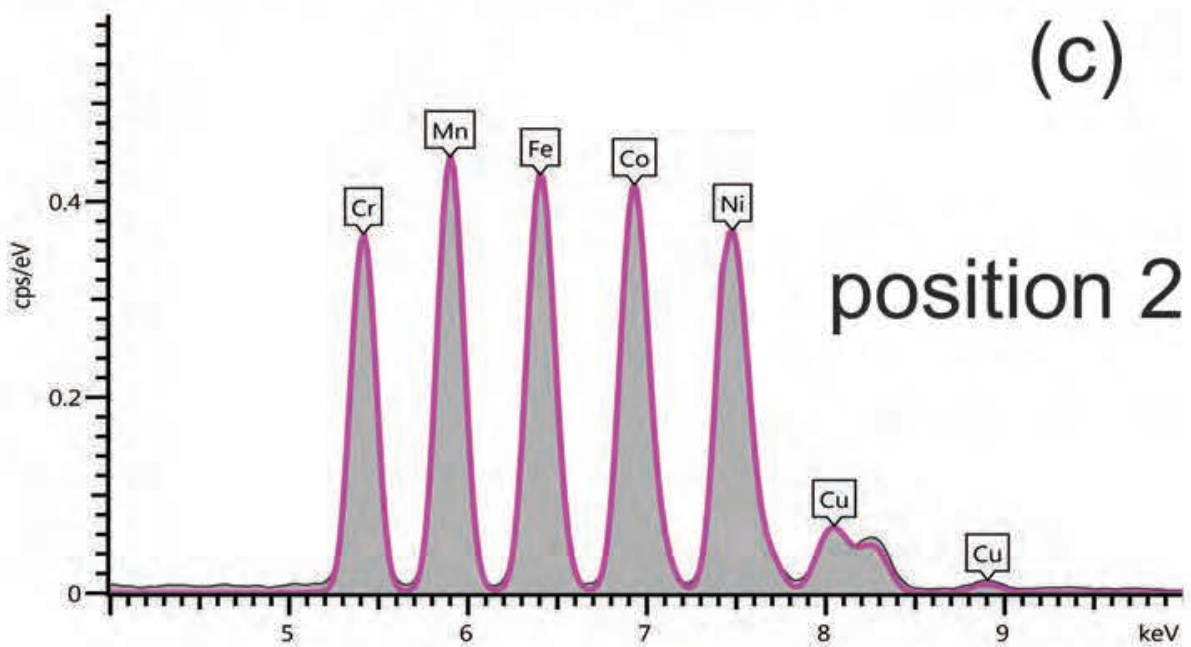


Fig. 6

(a) $\mathrm{Cr}$
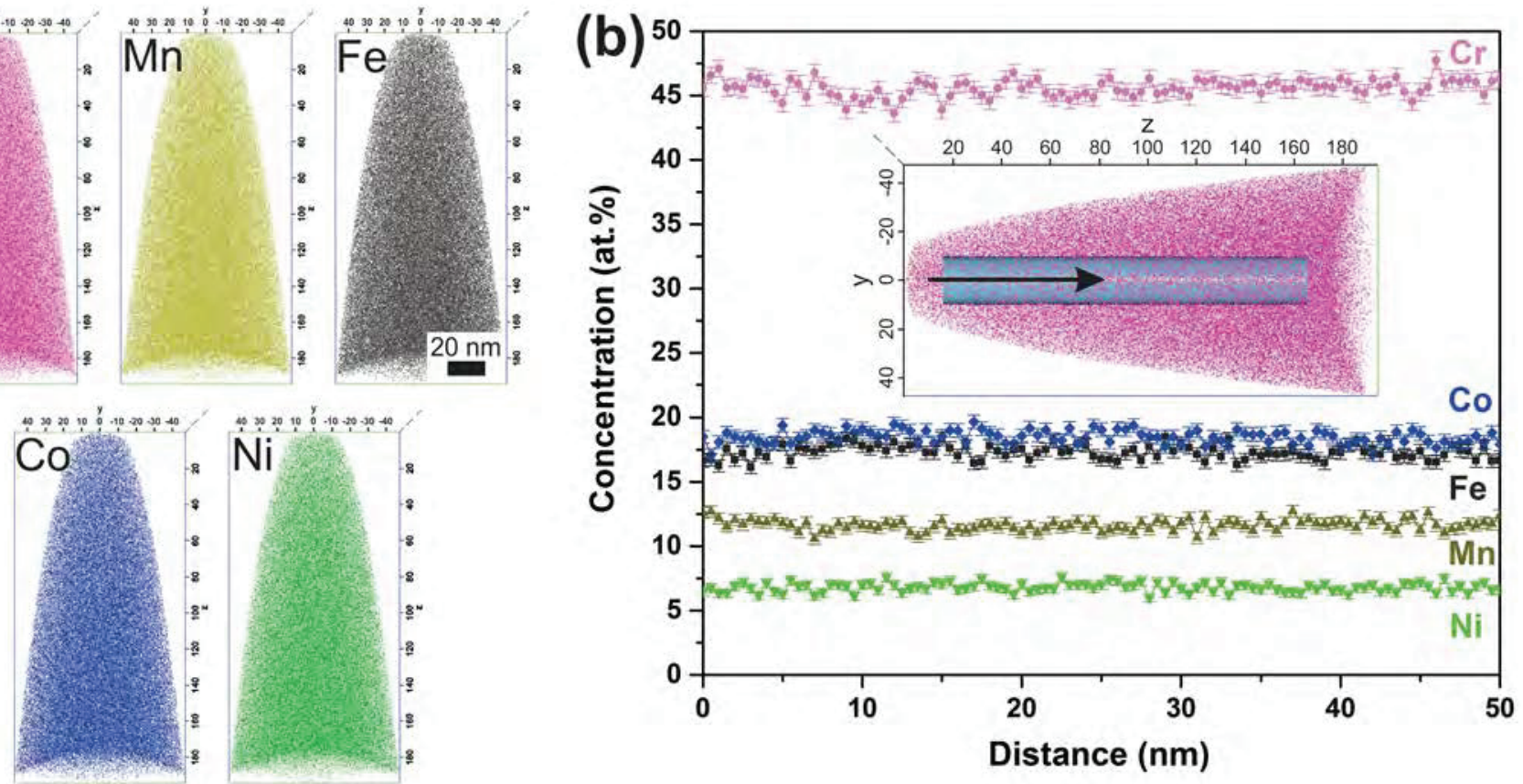
Fig. 7

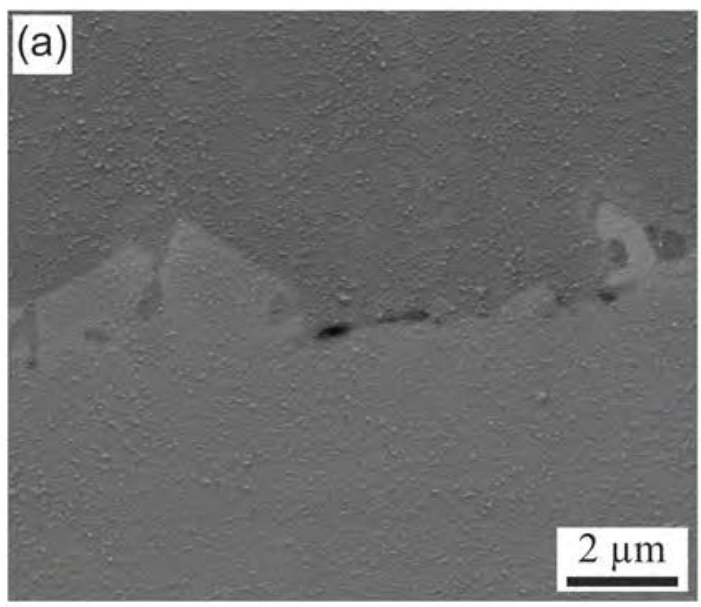

(b)

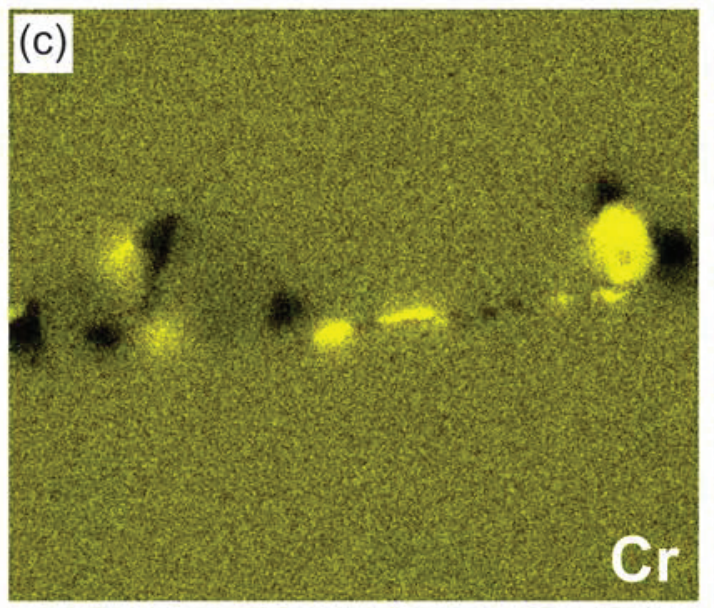

(d)

(e)

$\mathrm{Fe}$

Co

(f)

Mn

$\mathrm{Ni}$ 
Fig. 8
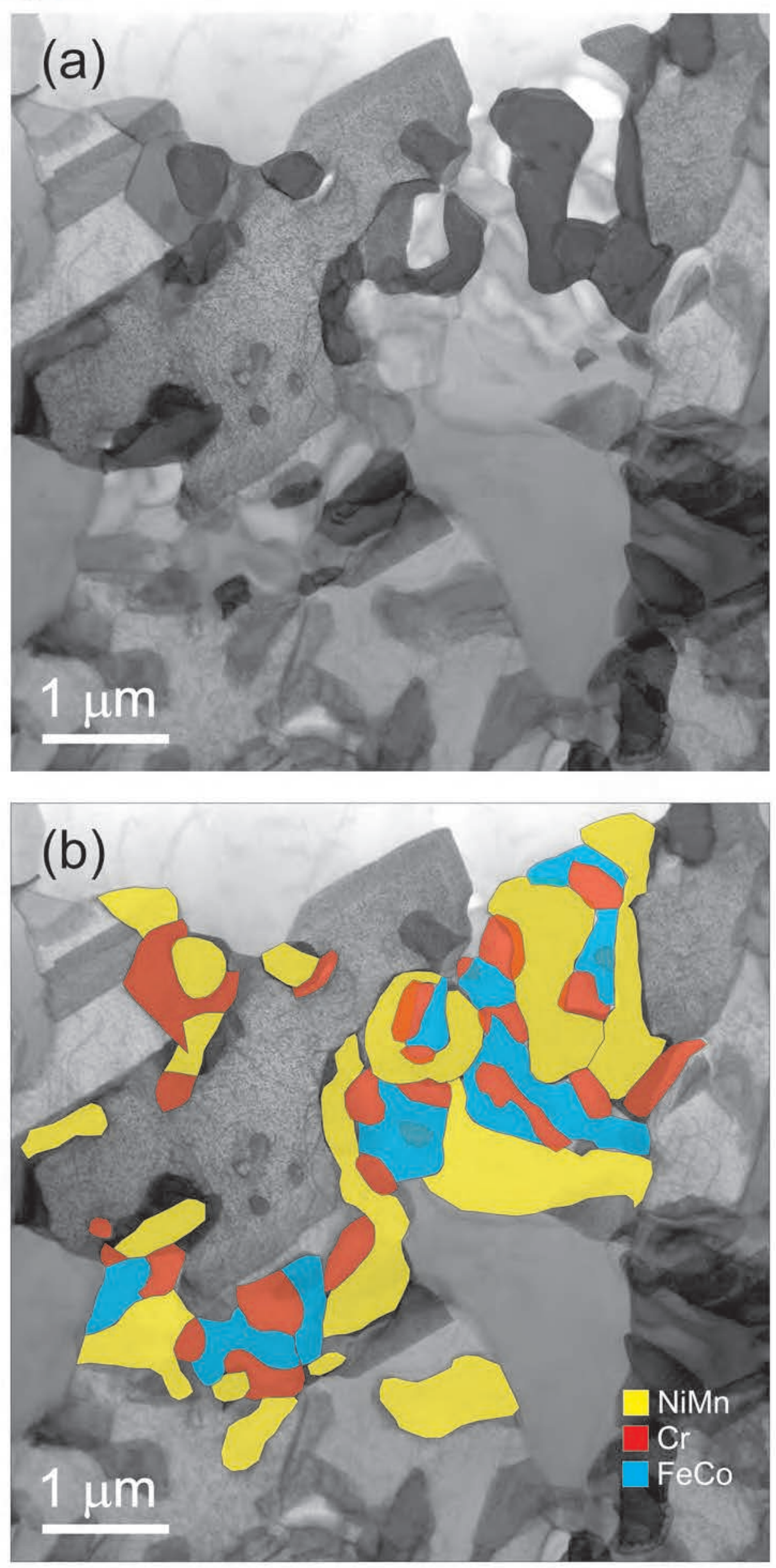
Fig. 9
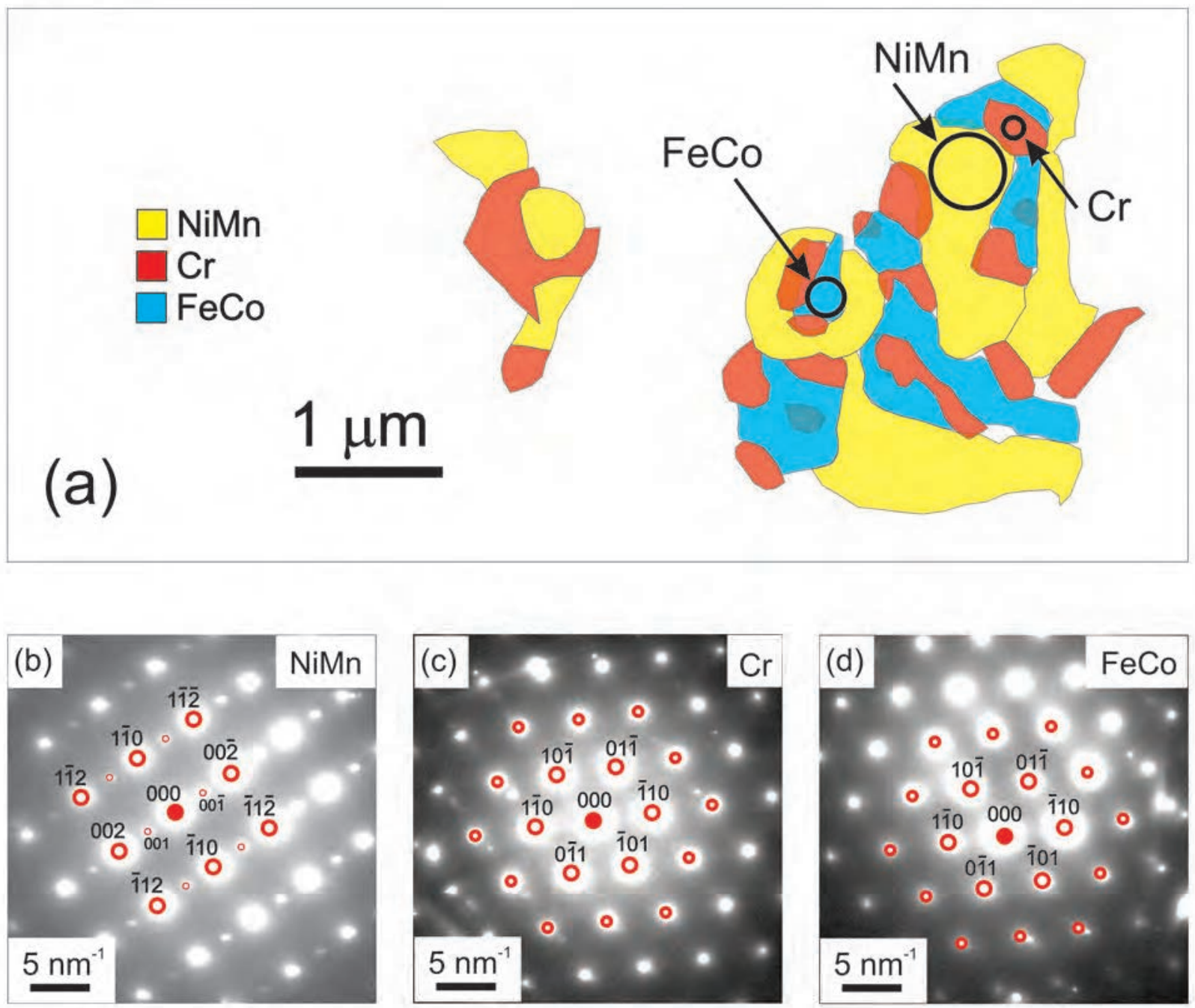
Fig. 10
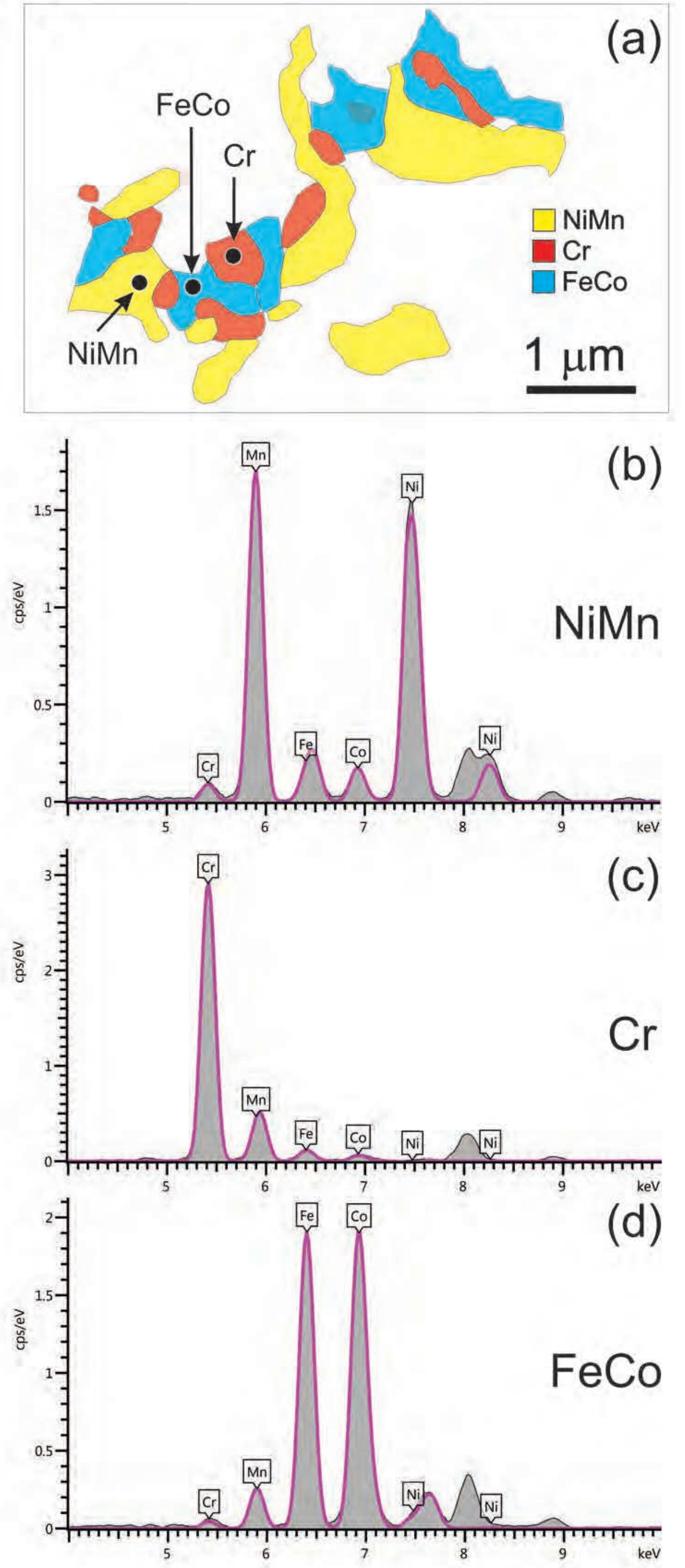
Fig. 11

(a) 20

$-10$

$-20$
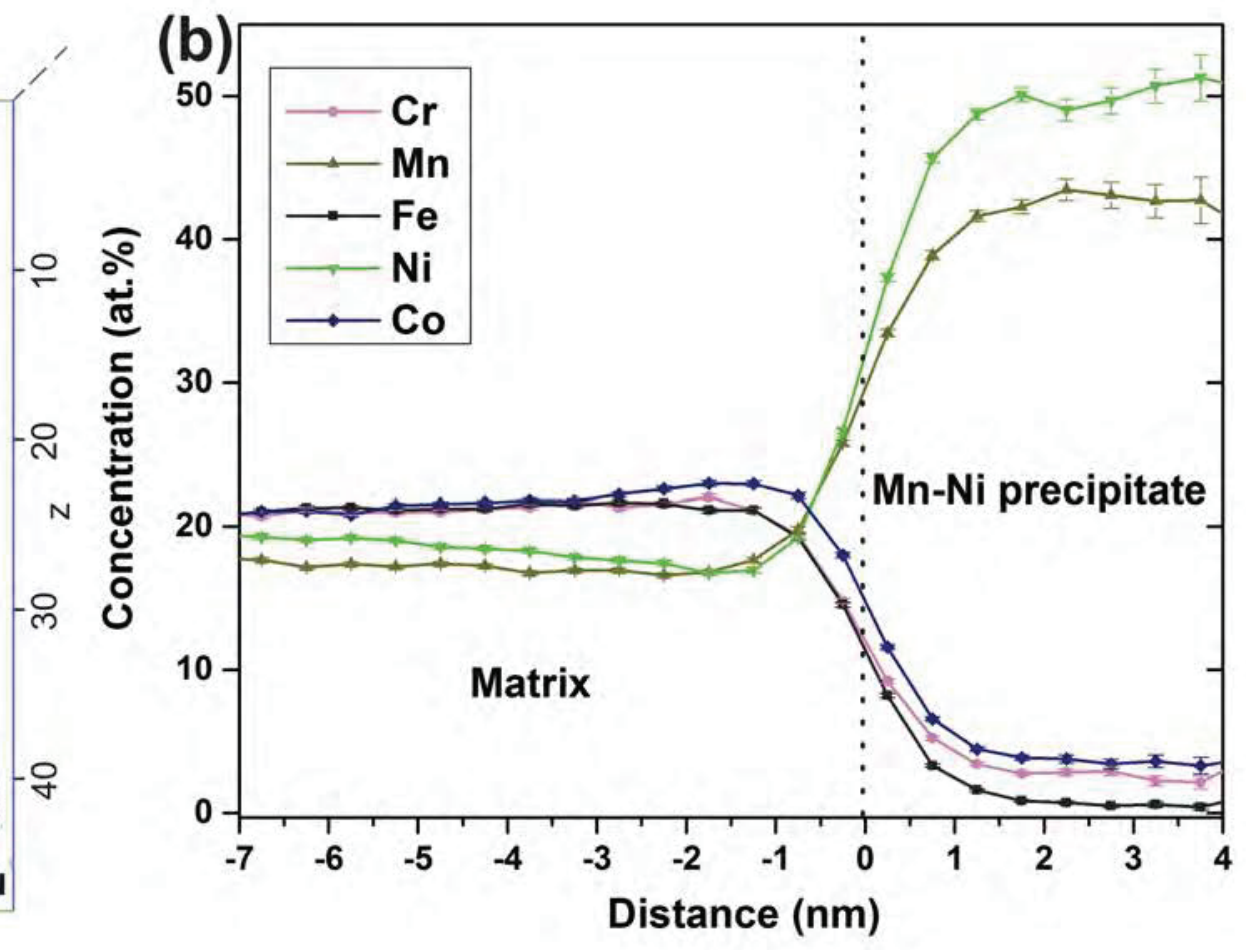
Fig. 12

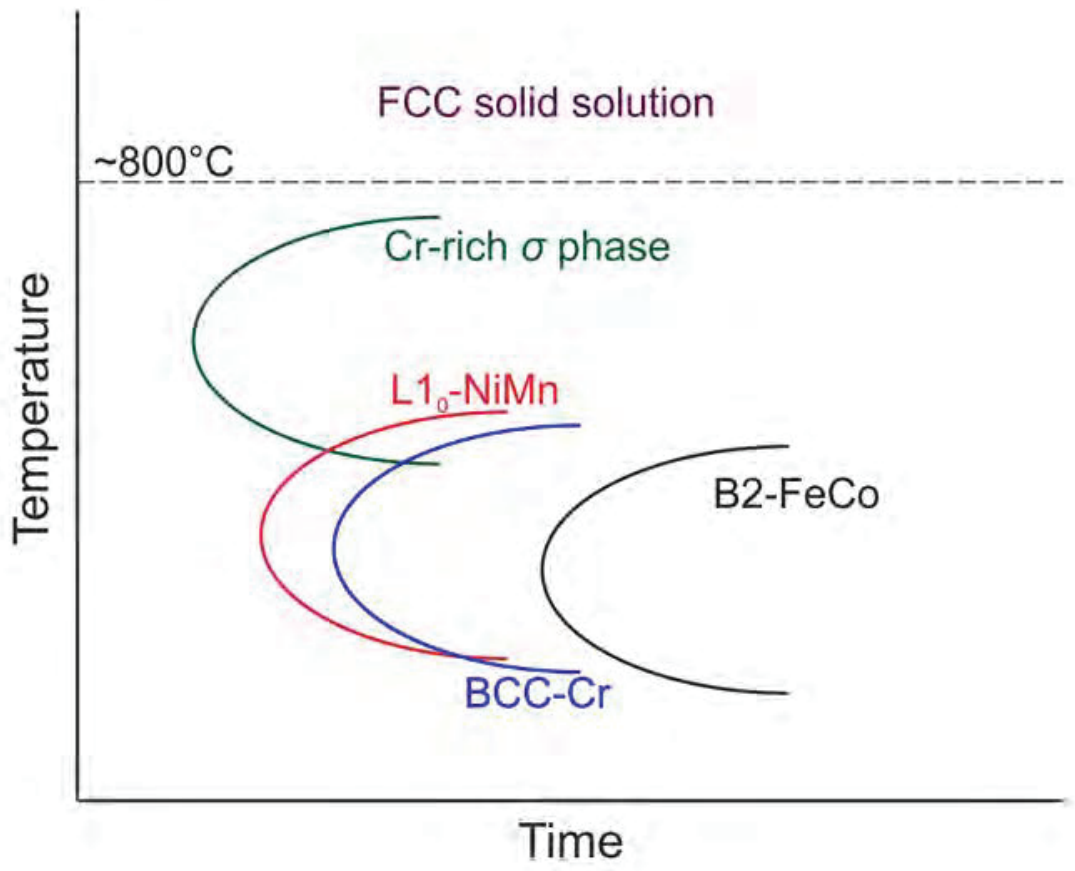




\section{Graphical Abstract}

$500 \mathrm{~d}$ at $900^{\circ} \mathrm{C}$

$$
\text { FCC solid solution }
$$

$500 \mathrm{~d}$ at $700^{\circ} \mathrm{C}$

$$
\mathrm{FCC}+\mathrm{Cr} \text {-rich } \sigma \text { phase }
$$

$500 \mathrm{~d}$ at $500^{\circ} \mathrm{C}$

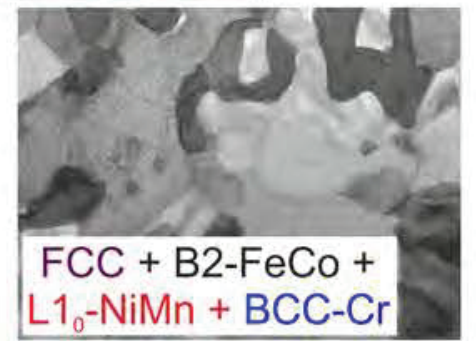

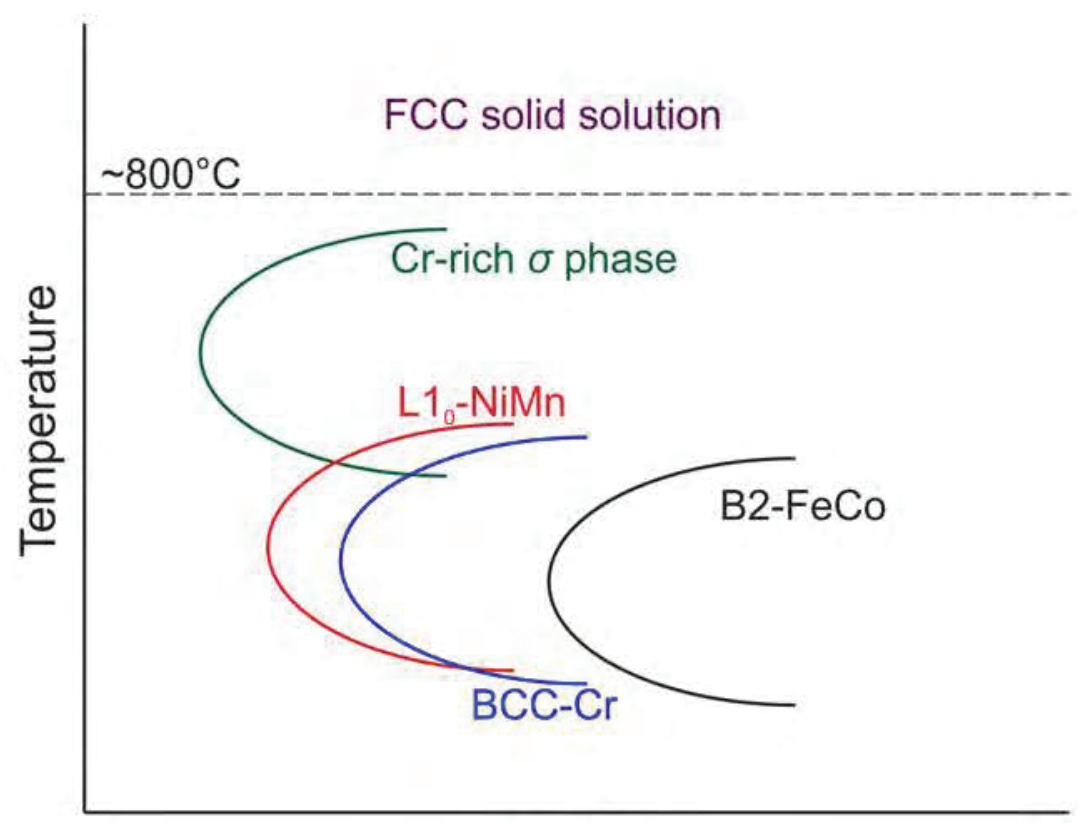

Time 